Molecules 2005, 10, 1318-1324

molecules

ISSN 1420-3049

http://www.mdpi.org

\title{
Synthesis of New Potentially Bioactive Bicyclic 2-Pyridones
}

Maxime D. Crozet ${ }^{1}$, Pascal George ${ }^{2}$, Michel P. Crozet ${ }^{1}$ and Patrice Vanelle ${ }^{1, *}$

${ }^{1}$ Laboratory of Pharmaceutical Organic Chemistry, CNRS UMR 6517, University of the Méditerranée (Aix - Marseille 2), Faculty of Pharmacy, 27 Bd Jean Moulin, 13385 Marseille Cedex 5, France. Fax +33 (0) 491794677 .

2 Sanofi-Synthélabo Recherche, Sanofi-Aventis, Central Nervous System Research Department, 31 Avenue Paul Vaillant Couturier, 92220 Bagneux, France.

* Author to whom correspondence should be addressed; E-mail: patrice.vanelle@pharmacie.univ$\underline{\text { mrs.fr }}$

Received: 6 June 2005; in revised form: 30 August 2005 / Accepted: 30 August 2005 / Published: 31 October 2005

Abstract: Three convenient methods of reduction of the nitro group of 5-nitroimidazoles and 5-nitrothiazole that bear a diethylmethylene malonate group in an ortho-like position with respect to the nitro group and cyclization of the resulting amino derivatives are reported. These reactions afforded the target bicyclic 2-pyridones in good to excellent yields.

Keywords: Nitro reduction, cyclization, bicyclic 2-pyridones, imidazopyridines, thiazolopyridines.

\section{Introduction}

As part of a program directed towards the synthesis of new bicyclic 2-pyridones of pharmaceutical interest bearing an ester group in the 6 position, we have reported a rapid alternative syntheses to the Knoevenagel reaction, and prepared nitroheterocycles containing a diethylmethylene malonate group in an ortho-like position with respect to the nitro group [1]. This paper describes the synthesis of bicyclic 2-pyridones in a two step procedure: reduction of the nitro group in 5-nitrothiazole and 5nitro-imidazole rings bearing the diethylmethylene malonate group followed by cyclization. 


\section{Results and Discussion}

Due to the high functionalization of the precursors of the pyridones (malonic acid diethyl ester, conjugated double bond, nitro group, heterocyclic ring with a nucleophilic heteroatom), we had to study the reduction reaction in order to selectively reduce the nitro group. Moreover, we studied the reactivity of the amino group obtained from the nitro group reduction and determined if the cyclization reaction could be made in a one-pot reduction-cyclization.

Many reagents can be used to reduce aromatic nitro compounds, the most common being $\mathrm{Zn}$, Sn or Fe (or sometimes other metals) under acidic conditions, or catalytic hydrogenation. Among other reagents we can also mention are $\mathrm{Al}-\mathrm{NiCl}_{2} \cdot 6 \mathrm{H}_{2} \mathrm{O}$-THF [2], titanium (II) [3] and titanium (III) [4] derivatives, $\mathrm{FeCl}_{3} \cdot 6 \mathrm{H}_{2} \mathrm{O}-\mathrm{H}_{2} \mathrm{~N}-\mathrm{N}\left(\mathrm{CH}_{3}\right)_{2}$ [5], $\mathrm{AlH}_{3}-\mathrm{AlCl}_{3}$, formic acid and Pd-C [6].

In our preliminary study we focused on imidazoles and our first choice to reduce the nitro group of diethyl 2-[(1,2-dimethyl-5-nitro- $1 H$-imidazol-4-yl)methylene]malonate (1) was a weak reducing agent, titanium(III) chloride (30 wt\% solution in $2 \mathrm{~N}$ hydrochloric acid) in a $\mathrm{H}_{2} \mathrm{O}$-acetone mixture at room temperature. The resulting intermediate was then heated in ethanolic sodium ethoxide solution to give the corresponding bicyclic pyridone 2 in 54\% yield (Scheme 1).

\section{Scheme 1.}

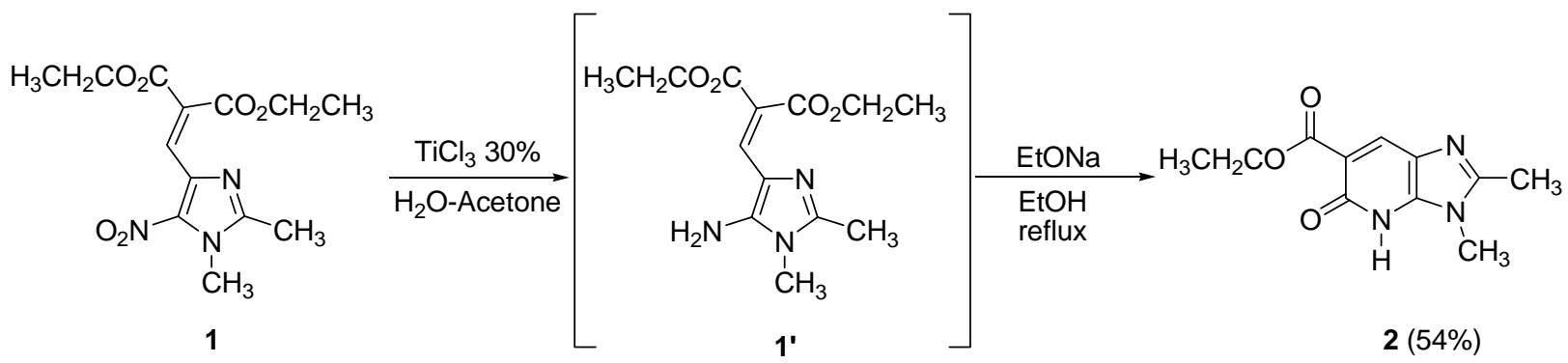

Unfortunately, this method was found to not be applicable to all nitroimidazoles. The 5-nitroimidazoles without alkyl substituents in the 2-position gave poor yields, so we had to find more general conditions and switched to other metal halides. We thus found that $\mathrm{SnCl}_{2}$ in ethanol gave the best results. Reduction of compound 3 occurred with five equivalents of $\mathrm{SnCl}_{2}$ in ethanol at $70{ }^{\circ} \mathrm{C}$, then the corresponding amine was treated with two equivalents of magnesium (powder) in methanol at room temperature during $20 \mathrm{~h}$ leading to the corresponding bicyclic pyridone $\mathbf{4}$ in 92\% yield (Scheme 2).

Scheme 2. 


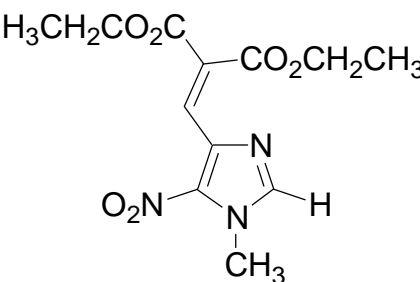

3
1) $\mathrm{SnCl}_{2}$ (5 equiv.)
$\underset{\mathrm{EtOH}, 70^{\circ} \mathrm{C}}{\mathrm{Mg}(2 \text { equiv. })}$
$\mathrm{MeOH}$<smiles>COC(=O)c1cc2ncc(=O)[nH]c2n1C</smiles>

$4(92 \%)$

The imidazopyridone $\mathbf{4}$ was obtained as the methyl ester due to the transesterification reaction in methanol. These conditions were applied to the $N$-ethyl imidazole analogue of 3 , but gave the imidazopyridone $\mathbf{6}$ in poor yield. No transesterification was observed in this case (Scheme 3).

\section{Scheme 3.}

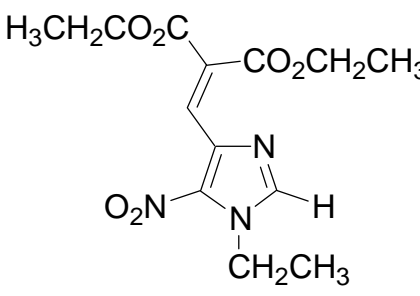

5

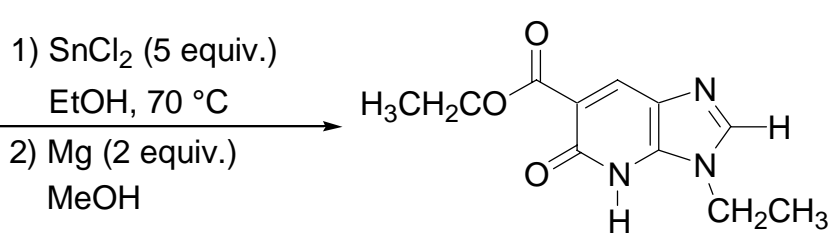

$6(27 \%)$

In order to obtain the imidazopyridone 7 containing a carboxylic acid ethyl ester moiety in the 6position, transesterification conditions with sodium ethoxide in ethanol (room temperature, $24 \mathrm{~h}$ ) were used from compound 4, leading to the desired bicycle 7 in excellent yield (92\%) (Scheme 4).

\section{Scheme 4.}

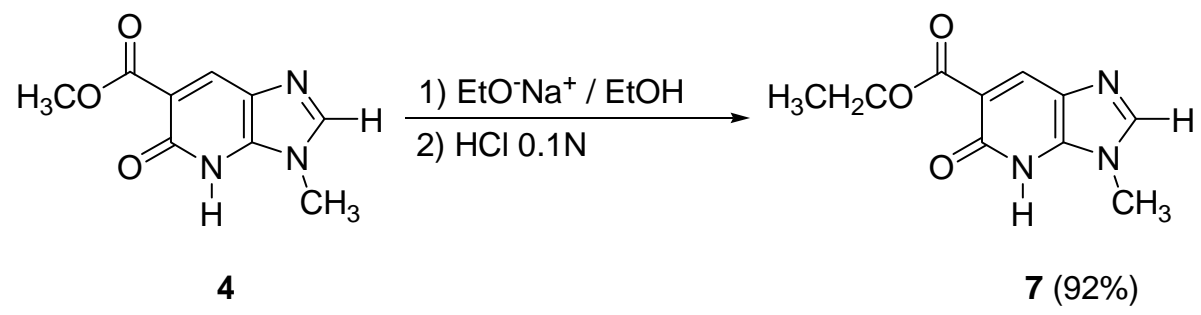

On the other hand, both the procedures previously described in this paper gave very poor yields of thiazolopyridone $\mathbf{9}$ when applied to the nitrothiazole 8. Consequently, we tried other reaction conditions using iron in glacial acetic acid as reported in our previous publication [7]. Under these conditions diethyl 2-[(2-methyl-5-nitrothiazol-4-yl)methylene]malonate (8) afforded the target lactam 9 in $90 \%$ yield (Scheme 5).

\section{Scheme 5.}




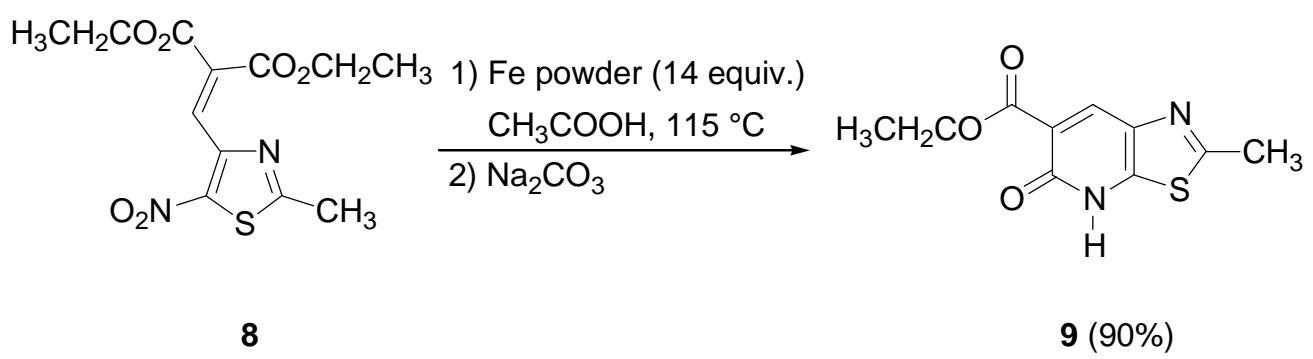

\section{Conclusions}

We have presented three convenient procedures for the synthesis of new bicyclic 2-pyridones from methylene malonic acid ethyl ester derivatives. Further studies are now in progress to determine the general character of these methods allowing reduction and cyclization of highly functionalized nitroheterocyclic compounds.

\section{Acknowledgements}

Financial support from Sanofi-Synthélabo Recherche and CNRS are highly appreciated. We are also grateful to Dr Mustapha Kaafarani and Dr Armand Gellis for fruitful discussions.

\section{Experimental}

\section{General}

Melting points were determined on a Büchi B-540 apparatus and are uncorrected. Elemental analyses were performed by the Centre de Microanalyses of The Paul Cézanne University (AixMarseille 3). Both ${ }^{1} \mathrm{H}$ - and ${ }^{13} \mathrm{C}$-NMR spectra were determined on a Bruker ARX 200 spectrometer. The ${ }^{1} \mathrm{H}$ chemical shifts were reported as parts per million downfield from chloroform-d $\left(\mathrm{CDCl}_{3}\right)$, and ${ }^{13} \mathrm{C}$ chemical shifts were referenced to the $\mathrm{CDCl}_{3}$ solvent peak (76.9 ppm). Silica gel 60 (Merck, 230-400 mesh) was used as adsorbent for column chromatography. Thin layer chromatography was performed with silica gel Merck 60F-254 (0.25 mm layer thickness). Diethyl 2-[(1,2-dimethyl-5-nitro-1Himidazol-4-yl)methylene]malonate (1), diethyl 2-[(1-methyl-5-nitro-1H-imidazol-4-yl)methylene]malonate (3) and diethyl 2-[(2-methyl-5-nitrothiazol-4-yl)methylene]malonate (8) were previously described [1].

Preparation of ethyl 2,3-dimethyl-5-oxo-4,5-dihydro-3H-imidazo[4,5-b]pyridine-6-carboxylate (2)

\section{a) Reduction using Titanium(III) chloride}

In a two-necked flask equipped with a reflux condenser, titanium(III) chloride (30 wt\% solution in $2 \mathrm{~N}$ hydrochloric acid, $21 \mathrm{~mL}$ ) were added dropwise on a solution of 1 (1.25 g, $4.02 \mathrm{mmol}$ ) in water (42 $\mathrm{mL})$ and acetone $(82 \mathrm{~mL})$. The mixture was stirred at room temperature for $20 \mathrm{~h}$. Then, a saturated aqueous solution of $\mathrm{Na}_{2} \mathrm{CO}_{3}$ was added. The green cake obtained was filtered and washed with 
dichloromethane, then, the solvent was dried over $\mathrm{MgSO}_{4}$ and removed under reduced pressure. The resulting amine was used for the cyclization reaction without any further purification.

\section{b) Cyclization using sodium ethoxide in ethanol}

In a two-necked flask equipped with a reflux condenser, ethanol (5 mL) and sodium (100 mg) were stirred until complete dissolution. A solution of the previously obtained amine in ethanol (45 mL) was added rapidly. This mixture was stirred at room temperature for $14 \mathrm{~h}$ and then at the reflux temperature of the ethanol for 2 additional hours. After cooling, water was added to the mixture, the solution was then extracted with chloroform. The combined organic layers were dried over $\mathrm{MgSO}_{4}$ and removed under vacuum. Purification by chromatography on silica gel eluting with ethyl acetate and recrystallization led to the corresponding product 2 (400 mg, 54\%). Yellow solid, mp $159.6{ }^{\circ} \mathrm{C}$ (ethyl acetate); ${ }^{1} \mathrm{H}-\mathrm{NMR}\left(\mathrm{CDCl}_{3}\right)$ \&: $1.44\left(\mathrm{t}, J=7.3 \mathrm{~Hz}, 3 \mathrm{H}, \mathrm{CH}_{2} \mathrm{CH}_{3}\right), 2.59$ (s, 3H, $\mathrm{CH}_{3}$ ), 3.73 (s, 3H, $\mathrm{NCH}_{3}$ ), 4.43 (q, $J=7.3 \mathrm{~Hz}, 2 \mathrm{H}, \mathrm{CH}_{2} \mathrm{CH}_{3}$ ), 8.42 (s, $\left.1 \mathrm{H}, \mathrm{Ar}-\mathrm{H}\right), 11.85$ (s, $\left.1 \mathrm{H}, \mathrm{NH}\right) ;{ }^{13} \mathrm{C}-\mathrm{NMR}\left(\mathrm{CDCl}_{3}\right)$

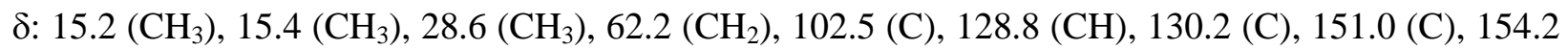
(C), 162.6 (C), 170.2 (C); Anal. Calcd for $\mathrm{C}_{11} \mathrm{H}_{13} \mathrm{~N}_{3} \mathrm{O}_{3}$ : C, 56.16; H, 5.57; N, 17.86. Found : C, 56.13; H, 5.53; N, 17.63 .

Preparation of methyl 3-methyl-5-oxo-4,5-dihydro-3H-imidazo[4,5-b]pyridine-6-carboxylate (4).

In a two-necked flask equipped with a reflux condenser, ethanol (32 mL), 3 (940 mg, $3.17 \mathrm{mmol}$ ) and tin(II) chloride ( $3 \mathrm{~g}, 15.83 \mathrm{mmol}$ ) were stirred at $70{ }^{\circ} \mathrm{C}$ for $1 \mathrm{~h}$. After cooling, the mixture was poured into an ice bath and made basic to $\mathrm{pH}=14$ with $1 \mathrm{~N}$ sodium hydroxide solution. The aqueous layer was then extracted with chloroform. The combined organic layer was dried over $\mathrm{MgSO}_{4}$ and evaporated. Methanol (47 mL) was added to the oil previously obtained, then magnesium metal turnings (154 mg, $6.22 \mathrm{mmol}$ ) were added. The mixture was stirred at room temperature for $16 \mathrm{~h}$ and acidified with $0.1 \mathrm{~N}$ hydrochloric acid. The aqueous layer was extracted with chloroform. The combined organic layer was dried over $\mathrm{MgSO}_{4}$ and evaporated to give $600 \mathrm{mg}$ (92\% yield) of 4 as a brown solid. Mp $345.1{ }^{\circ} \mathrm{C}$ (ethanol/ethyl acetate: 2:1); ${ }^{1} \mathrm{H}-\mathrm{NMR}\left(\mathrm{CDCl}_{3}\right) \delta: 3.84$ (s, 3H, $\mathrm{CH}_{3}$ ), 4.01 (s, $3 \mathrm{H}, \mathrm{OCH}_{3}$ ), 8.01 (s, $\left.1 \mathrm{H}, \mathrm{Ar}-\mathrm{H}\right), 8.60$ (s, $\left.1 \mathrm{H}, \mathrm{Ar}-\mathrm{H}\right), 11.81$ (s, $\left.1 \mathrm{H}, \mathrm{NH}\right) ;{ }^{13} \mathrm{C}-\mathrm{NMR}\left(\mathrm{CDCl}_{3}\right) \delta: 29.8$ $\left(\mathrm{CH}_{3}\right), 52.9\left(\mathrm{CH}_{3}\right), 103.2(\mathrm{C}), 129.9(\mathrm{C}), 132.0(\mathrm{CH}), 145.2(\mathrm{CH}), 149.8(\mathrm{C}), 163.1(\mathrm{C}), 170.5(\mathrm{C})$. Anal. Calcd for $\mathrm{C}_{9} \mathrm{H}_{9} \mathrm{~N}_{3} \mathrm{O}_{3}$ : C, 52.17; H, 4.38; N, 20.28. Found : C, 52.02; H, 4.38; N, 19.98.

Preparation of ethyl 3-ethyl-5-oxo-4,5-dihydro-3H-imidazo[4,5-b]pyridine-6-carboxylate (6).

Following the procedure described for 4, $200 \mathrm{mg}$ (27\% yield) of ethyl 3-ethyl-5-oxo-4,5-dihydro$3 \mathrm{H}$-imidazo[4,5-b]pyridine-6-carboxylate (6) was obtained as a yellow solid, mp $102.5{ }^{\circ} \mathrm{C}$ (ethanol); ${ }^{1} \mathrm{H}-\mathrm{NMR}\left(\mathrm{CDCl}_{3}\right) \delta: 1.44$ (t, $\left.J=7.1 \mathrm{~Hz}, 3 \mathrm{H}, \mathrm{CH}_{2} \mathrm{CH}_{3}\right), 1.52$ (t, $\left.J=7.3 \mathrm{~Hz}, 3 \mathrm{H}, \mathrm{CH}_{2} \mathrm{CH}_{3}\right), 4.26$ (q, $J=$ $7.3 \mathrm{~Hz}, 2 \mathrm{H}, \mathrm{CH}_{2} \mathrm{CH}_{3}$ ), 4.45 (q, $J=7.1 \mathrm{~Hz}, 2 \mathrm{H}, \mathrm{CH}_{2} \mathrm{CH}_{3}$ ), 7.97 (s, $\left.1 \mathrm{H}, \mathrm{Ar}-\mathrm{H}\right), 8.58$ (s, $\left.1 \mathrm{H}, \mathrm{Ar}-\mathrm{H}\right), 11.87$ (s, 1H, NH); ${ }^{13} \mathrm{C}-\mathrm{NMR}\left(\mathrm{CDCl}_{3}\right) \delta: 14.1\left(\mathrm{CH}_{3}\right), 15.3\left(\mathrm{CH}_{3}\right), 38.6\left(\mathrm{CH}_{2}\right), 62.1\left(\mathrm{CH}_{2}\right), 103.5(\mathrm{C}), 130.0$ (C), $131.9(\mathrm{CH}), 144.0(\mathrm{CH}), 149.2(\mathrm{C}), 163.0(\mathrm{C}), 170.1(\mathrm{C})$; Anal. Calcd for $\mathrm{C}_{11} \mathrm{H}_{13} \mathrm{~N}_{3} \mathrm{O}_{3}$ : C, 56.16; H, 5.57; N, 17.86. Found : C, 56.25; H, 5.57; N, 17.25 . 
Preparation of ethyl 3-methyl-5-oxo-4,5-dihydro-3H-imidazo[4,5-b]pyridine-6-carboxylate (7).

In a two-necked flask equipped with a reflux condenser, ethanol $(10 \mathrm{~mL})$ and sodium $(0.03 \mathrm{~g}, 1.3$ $\mathrm{mmol}$ ) were stirred at room temperature. After formation of the sodium ethoxide, a solution of 4 ( $0.2 \mathrm{~g}$, $0.97 \mathrm{mmol})$ in ethanol $(10 \mathrm{~mL})$ was added dropwise. The mixture was stirred at room temperature for $48 \mathrm{~h}$, then it was acidified with $0.1 \mathrm{~N}$ hydrochloric acid to $\mathrm{pH}=4$. The aqueous layer was extracted with chloroform. The combined organic layer was dried over $\mathrm{MgSO}_{4}$ and evaporated to give $200 \mathrm{mg}$ of 7 (92\% yield). An analytical sample of 7 (yellow solid, mp $164.0{ }^{\circ} \mathrm{C}$ ) was obtained by crystallization (ethanol); ${ }^{1} \mathrm{H}-\mathrm{NMR}\left(\mathrm{CDCl}_{3}\right.$ ) $\delta: 1.44$ (t, $J=7.1 \mathrm{~Hz}, 3 \mathrm{H}, \mathrm{CH}_{2} \mathrm{CH}_{3}$ ), 3.83 (s, 3H, $\mathrm{CH}_{3}$ ), 4.45 (q, $J=7.1$ $\mathrm{Hz}, 2 \mathrm{H}, \mathrm{CH}_{2} \mathrm{CH}_{3}$ ), 7.94 (s, $\left.1 \mathrm{H}, \mathrm{Ar}-\mathrm{H}\right), 8.60$ (s, $\left.1 \mathrm{H}, \mathrm{Ar}-\mathrm{H}\right), 11.89$ (s, $\left.1 \mathrm{H}, \mathrm{NH}\right) ;{ }^{13} \mathrm{C}-\mathrm{NMR}\left(\mathrm{CDCl}_{3}\right) \delta$ : $14.1\left(\mathrm{CH}_{3}\right), 29.8\left(\mathrm{CH}_{3}\right), 62.2\left(\mathrm{CH}_{2}\right), 103.5(\mathrm{C}), 129.3(\mathrm{C}), 129.8(\mathrm{C}), 132.0(\mathrm{CH}), 145.1(\mathrm{CH}), 163.3$ (C), 170.1 (C). Anal. Calcd for $\mathrm{C}_{10} \mathrm{H}_{11} \mathrm{~N}_{3} \mathrm{O}_{3}$ : C, 54.29; H, 5.01; N, 19.00. Found : C, 54.27; H, 4.96; $\mathrm{N}, 18.76$.

Preparation of ethyl 2-methyl-5-oxo-4,5-dihydrothiazolo[5,4-b]pyridine-6-carboxylate (9).

In a two-necked flask equipped with a reflux condenser, 8 (100 mg, $0.314 \mathrm{mmol})$ and glacial acetic acid (5 mL) were stirred and heated at reflux. To this solution was added iron powder (250 mg, 4.46 mmol) and the stirred mixture was heated at reflux for $2 \mathrm{~h}$. After cooling, the solution was filtered through Celite and washed with glacial acetic acid. The acetic acid solution was evaporated on a rotary evaporator and the residue made basic with aqueous $\mathrm{Na}_{2} \mathrm{CO}_{3}$. The aqueous layer was extracted with chloroform. The combined organic layer was dried over $\mathrm{MgSO}_{4}$ and evaporated to give $70 \mathrm{mg}$ of 9 (90\% yield). An analytical sample of 9 was obtained as a beige solid, mp $114.6^{\circ} \mathrm{C}$, by crystallization (isopropanol); ${ }^{1} \mathrm{H}-\mathrm{NMR}\left(\mathrm{CDCl}_{3}\right) \delta: 1.43\left(\mathrm{t}, J=6.8 \mathrm{~Hz}, 3 \mathrm{H}, \mathrm{CH}_{2} \mathrm{CH}_{3}\right), 2.78\left(\mathrm{~s}, 3 \mathrm{H}, \mathrm{CH}_{3}\right), 4.46$ (q, $J=$ $\left.6.8 \mathrm{~Hz}, 2 \mathrm{H}, \mathrm{CH}_{2} \mathrm{CH}_{3}\right), 8.61$ (s, $\left.1 \mathrm{H}, \mathrm{Ar}-\mathrm{H}\right), 11.63$ (s, $\left.1 \mathrm{H}, \mathrm{NH}\right) ;{ }^{13} \mathrm{C}-\mathrm{NMR}\left(\mathrm{CDCl}_{3}\right) \delta: 14.0\left(\mathrm{CH}_{3}\right), 20.8$ $\left(\mathrm{CH}_{3}\right), 62.6\left(\mathrm{CH}_{2}\right), 106.3(\mathrm{C}), 132.3(\mathrm{CH}), 141.2(\mathrm{C}), 162.4(\mathrm{C}), 163.6(\mathrm{C}), 166.1(\mathrm{C}), 169.3(\mathrm{C})$; Anal. Calcd for $\mathrm{C}_{10} \mathrm{H}_{10} \mathrm{~N}_{2} \mathrm{O}_{3} \mathrm{~S}: \mathrm{C}, 50.41 ; \mathrm{H}, 4.23 ; \mathrm{N}, 11.76$. Found : C, 50.44; H, 4.20; N, 11.68.

\section{References}

1. Crozet, M. D.; Perfetti, P.; Kaafarani, M.; Crozet, M. P.; Vanelle, P. Rapid syntheses of nitroheterocycles that bear a diethyl methylenemalonate group $\beta$ to a nitro group. Lett. Org. Chem. 2004, 1, 326-330.

2. Sarmah, P.; Barua, N. C. A facile reduction procedure for nitroarenes with Al-NiCl $-\mathrm{THF}$ system. Tetrahedron Lett. 1990, 31, 4065-4066.

3. George, J.; Chandrasekaran, S. Selective reduction of nitro compounds with titanium(II) reagents. Synth. Commun. 1983, 13, 495-499.

4. Ho, T.-L.; Wong, C. M. Reduction of aromatic nitro compounds by titanium(III) chloride. Synthesis 1974, 45.

5. Boothroyd, S. R.; Kerr, M. A. A mild and efficient method for the preparation of anilines from nitroarenes. Tetrahedron Lett. 1995, 36, 2411-2414. 
6. Entwistle, I. D.; Jackson, A. E.; Johnstone, R. A. W.; Telford, R. P. Reduction of nitro compounds. J. Chem. Soc., Perkin Trans. 1 1977, 443-444.

7. Crozet, M. D.; Suspène, C.; Kaafarani, M.; Crozet, M. P.; Vanelle, P. Synthesis of a new imidazo[4,5-b]pyridin-5-one via a vicarious nucleophilic substitution of hydrogen. Heterocycles 2004, 63, 1629-1635.

Sample Availability: Available from the authors.

(c) 2005 by MDPI (http:www.mdpi.org). Reproduction is permitted for noncommercial purposes. 